\title{
Local Scour of Bridge Pier Sited on a Multi- Layered Sedimentary Bed in Rivers
}

\author{
Shaolin Y ue ${ }^{1}$, Huan Zhou ${ }^{1}$, Wenlong Zhu², and Minxi Zhang ${ }^{2, *}$ \\ ${ }^{1}$ CCCC Road \& B ridge Special Engineering Co., L td., W uhan, Hubei 430071, China \\ 2 SK LOE, CISSE, School of Naval A rchitecture, Ocean \& Civil Engineering, Shanghai Jiao Tong \\ University, Shanghai 200240, China.
}

\begin{abstract}
The riverbeds or sea beds are usually composed of multi-layers of sediments. The scour around bridge piers sited on such beds is vital to the bridge safety, but is still very difficult to be predicated as its complicated interaction between the flow and bed layers. A simple model is proposed in this study for calculating the local scour maximum depth around bridge piers sited on multi-layer of sedimentary bed, which is based on HEC-18 formula revised by Richardson and Davis (2001) and the formula of the repose angle of sediment particles proposed by Cheng (1993). This model considers the particle sorting when the scour proceeds. An application of the model into the local scour depth of Guopan bridge pier sited on the Weihe River bed in Baoji city of China preliminarily demonstrates its reliability to calculate the local scour maximum depth around bridge piers sited on multi-layer of sedimentary bed.
\end{abstract}

\section{Introduction}

Pier scour would strongly affect the safety of bridges. It is important to accurate predict the pier scour with non-uniform sediments for given hydraulic and geometric conditions. The removal of sediments from river bed around a bridge pier caused by running water is called as local scour of bridge pier. Bridge local scour is one of the major causes of bridge failure. It was statistically found that the scour was accountable for about $60 \%$ of bridge failures $[1,2]$ resulting in loss of lives and huge economic losses. Among the documented 1502 bridge failures data in the United State from 1996 to 2005, 58\% were the result of the hydraulic conditions [3]. Up to now, there are still many bridges collapsed every year in the world yielded by scouring. These scour results in not only exposure of the foundation, but also endangers to the stability of the bridges. It was found that the storm Alberto caused flooding damages to over 500 bridges in Georgia and the damage due to scour costed $\$ 130$ million [4]. Hence, the estimation of local scour of bridge pier is an important essential factor in designing bridges.

Up to now, there are numerous empirical formulae for the calculation of the maximum scour depth around bridge pier [5-10]. Many clear water scour experiments were carried out and equations were derived to estimate the equilibrium scour depth, which mainly

\footnotetext{
* Corresponding author: zmx8888@ sjtu.edu.cn
} 
considered approach flow depth, velocity, pier diameter, shape of the pier, flow attack angle and median sediment grain size. With non-uniform sediments, the maximum scour depth is smaller than or equal to that with uniform sediments of the same median grain size $d_{50}$ [11]. Some investigators have considered the effect of grain size distribution on the local depth of scour at a bridge pier in their scour analyses [12-14]. However, unlike piers sited in single layer of non-uniform sedimentary bed, experimental data and studies done on the pier scour in multi-layers of bed with different sizes of sediments were few in the past. There are few efforts on estimating the scour depth around bridge piers sited in multilayered bed with different sizes of sediments. Porter et al. [15-16] investigated the scour development around a circular cylinder in layered and mixed granular sediments. The calculation of maximum scour depth of bridge piers sited on multi-layered sedimentary beds is still a challenge to hydraulic scientists and engineers.

The objective of this paper is to find a method to calculate the maximum scour depth of bridge piers sited on multi-layered sedimentary beds. A formula considering the sediment mixture and armoring process during scour hole formation process is proposed. A field survey was conducted and the scour depth of the piers at Guopan bridge in Baoji City of China is analyzed. Finally, this model is successfully compared with the field survey data.

\section{Model for Local Scour Prediction of Pier on Multi-Layered Bed}

The particle sorting when the pier scour proceeds should be considered for multi-layered beds. A model is proposed in this study for the calculation of local scour maximum depth around bridge piers sited on multi-layer of sedimentary bed, which is based on HEC-18 revised by Richardson and Davis [4] and the formula of the repose angle of sediment particles proposed by Cheng [17]. The HEC-18 equation for the local scour depth calculation was modified by Richardson and Davis ${ }^{[4]}$ as:

$$
\frac{h_{s}}{h_{0}}=2.0 K_{1} K_{2} K_{3} K_{4}\left(\frac{b}{h_{0}}\right)^{0.65} F_{0}^{0.43}
$$

where $h_{s}$ is the maximum scour depth; $h_{0}$ is the water depth; $b$ is the equivalent width of the bridge pier; $F_{0}$ is the Froude number; $K_{l}$ is the shape coefficient of pier nose (1.1 for square-nose piers, 1.0 for circular or elliptical-nose pier, 0.9 for sharp nose pier and 1.0 for cylinder group); $K_{2}$ is the coefficient which is related to the length width ratio of pier and the angle between the approach flow and pier alignment; $K_{3}$ is the shape coefficient of bed surface; $K_{4}$ is the bed material coefficient, which is defined as:

where $V_{R}$ is written as:

$$
K_{4}=\left[1-0.89\left(1-V_{R}\right)^{2}\right]^{0.5}
$$

$$
V_{R}=\frac{V_{0}-V_{C}^{\prime}}{V_{c D 90}-V_{C}^{\prime}}
$$

where $V_{0}$ is the approach velocity, $V_{c}^{\prime}$ is the approach velocity enable the sediment with size $D_{50}$ to start at the site of the pier, which is written as:

$$
\begin{gathered}
V_{C}^{\prime}=0.645\left(\frac{D_{50}}{b}\right)^{0.053} V_{c D_{50}} \\
V_{c D_{50}}=11.2 h_{0}^{1 / 6} D_{50}^{1 / 3}
\end{gathered}
$$

Correspondingly, the threshold velocity for the sediment with size $D_{90}$ can be written as:

$$
V_{c D_{90}}=11.2 h_{0}^{1 / 6} D_{90}^{1 / 3}
$$

When $V_{R}>1.0, K_{4}=1.0$. If $D_{50}$ is larger than $60 \mathrm{~mm}, K_{4}$ has to be corrected and $K_{4}$ is not smaller than 0.7.

The calculation process of local scour of pier in multi-layered bed (Fig. 1) can be described as 
1) Using the median sediment size $d_{50}$ of the first layer of the bed to calculate the local scour depth of the pier, $h_{s l}$. Calculate the minimum size $d_{a l}$ of bed sediments in the scour hole supposing the downstream slope of the scour hole is identical to the repose angle of the median size of the first layer. Calculate the scour hole volume $V_{s l}$ and the armor amount in the scour hole $V_{a l}$. Then, using $d_{a l}$ to calculate the local scour depth of the pier, and repeat the above process till the calculated $h_{s l}$ remains.

The repose angle is calculated by the following formula proposed by Cheng [17]:

$$
\operatorname{tg} \varphi=0.457\left(\frac{\sqrt{g d} d}{v}\right)^{0.05}\left(\frac{\rho_{s}-\rho}{\rho}\right)^{0.106} S_{f}^{-0.8} \eta^{0.12}
$$

where $d$ is the sediment size; $n$ is the kinetic viscosity of the medium; $S_{f}$ is the shape factor of sediment particles, $\rho$ is the medium density and $\rho_{s}$ is the sediment density, $h=d_{75} / d_{25}$. In Eq. (7), it is assumed that $S_{f} \approx 0.7$ for natural sediment particles.

2) Compare the thickness $h_{b l}$ and scour depth $h_{s l}$.

If $h_{b l} \geq h_{s l}$, then the local scour depth is $h_{s l}$.

If $h_{b l}<h_{s l}$, then using the sediment size quantities of the second layer of the bed to calculate the local scour depth of the pier, $h_{s 2}$. Calculate the minimum size $d_{a 2}$ of bed sediments in the scour hole supposing the downstream slope of the scour hole within the second layer is identical to the repose angle of the median size of the second layer. Calculate the scour hole volume $V_{s 2}$ and the armor amount in the scour hole $V_{a 2}$. Then, using $d_{a 2}$ of the armored layer on the bottom to calculate the local scour depth of the pier, and repeat the above process till calculated $h_{s 2}$ remains.

3) Compare the thickness $h_{b 2}$ and scour depth $h_{s 2}$.

If $h_{b 1} \geq h_{s 2}$, then the local scour depth is $h_{b 1}$. If $h_{b 1}+h_{b 2} \geq h_{s 2}$, then the local scour depth is $h_{s 2}$. If $h_{b 1}+h_{b 2}<h_{s 2}$, calculate the $h_{s 3}$ of the third layer similar to (1) and (2).

4) Calculate the $h_{s n}$ of the $n^{t h}$ layer until the $h_{b n}>h_{s n}$ and the calculation stops.

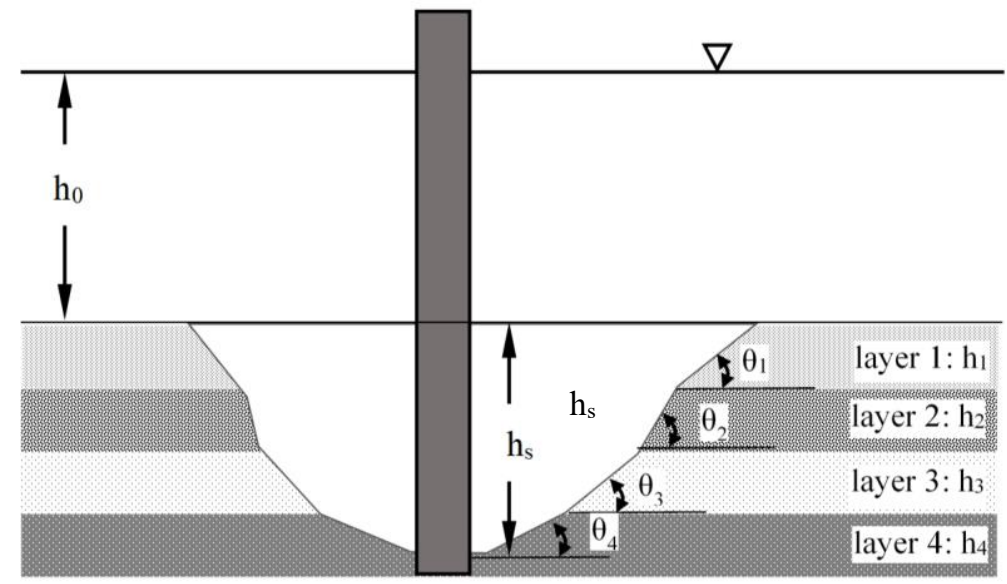

Fig.1. Simplified scour hole

\section{Application of the Model}

The Guopan bridge was completed in May 1984, with a total length of $644.54 \mathrm{~m}$. Its 32 piers (each with two circular piles) are sited in multi-layers of sedimentary channel bed as depictured in Figs. 2 and 3, which are located in the upper reaches of the Weihe River in in Baoji city of China, with a drainage area of $30661 \mathrm{~km}^{2}$. The superstructure of the bridge is a simply supported T-beam with a span of $20 \mathrm{~m}$, with a height of about $1.2 \mathrm{~m}$; the substructure is a single row of two $1.2 \mathrm{~m}$ diameter cylindrical piers and pile foundations. 


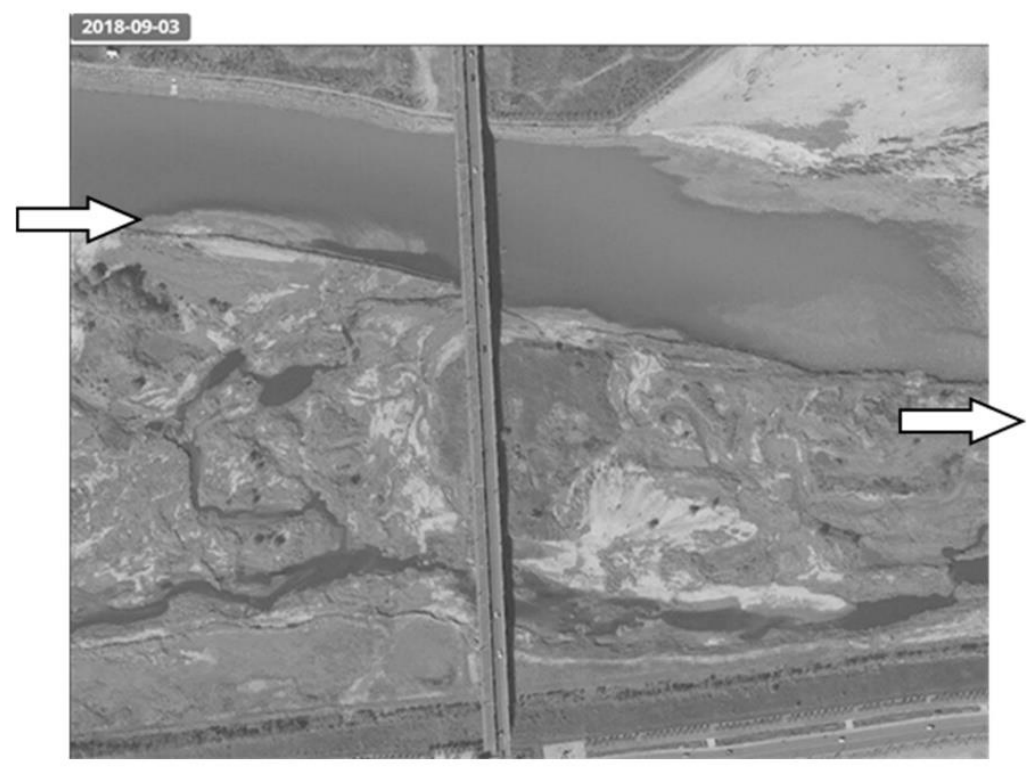

Fig. 2. The Guopan B ridge cross the W eihe River

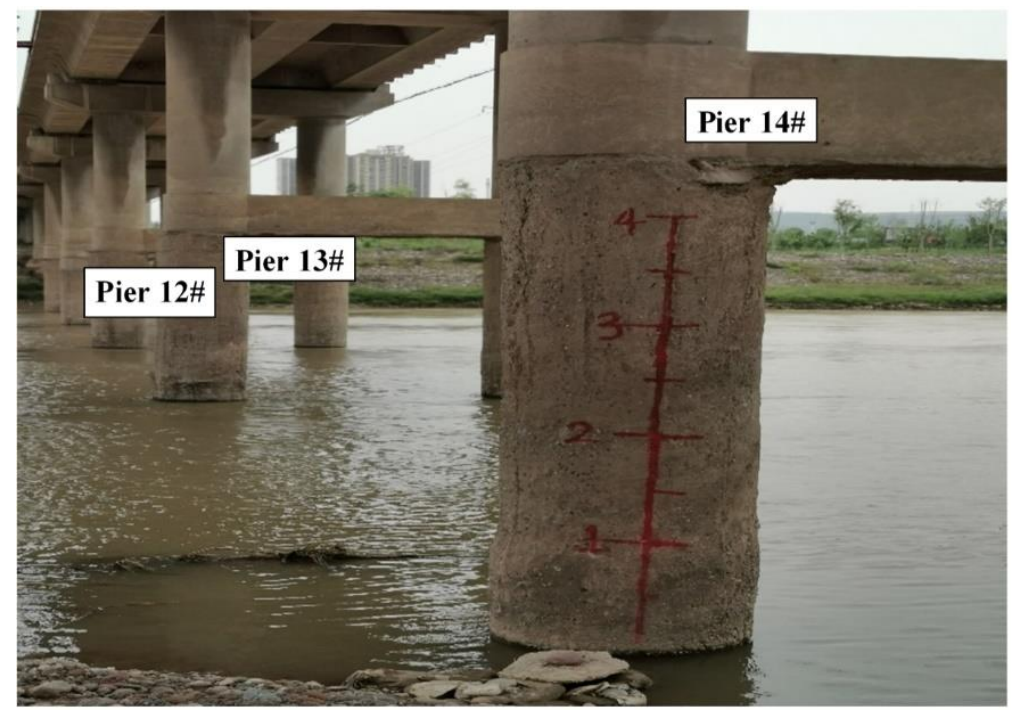

Fig. 3. Scoured piers

The riverbed and riverbank in this reach are mostly composed of sands, gravels and pebbles. The width of the channel is about $400-680 \mathrm{~m}$, and the gradient of the channel is $1.35 \%$. Weihe River is a sediment laden river in the flood season (June to October). The maximum flow of Weihe River is $4800 \mathrm{~m}^{3} / \mathrm{s}$ in 20 -year return period, $5660 \mathrm{~m}^{3} / \mathrm{s}$ in 30 -year return period, $6440 \mathrm{~m}^{3} / \mathrm{s}$ in 50 -year return period, $7450 \mathrm{~m}^{3} / \mathrm{s}$ in 100 -year return period. The angle between river flow direction and the pier piles (attack angle of the flow) is about $15^{\circ}$. 


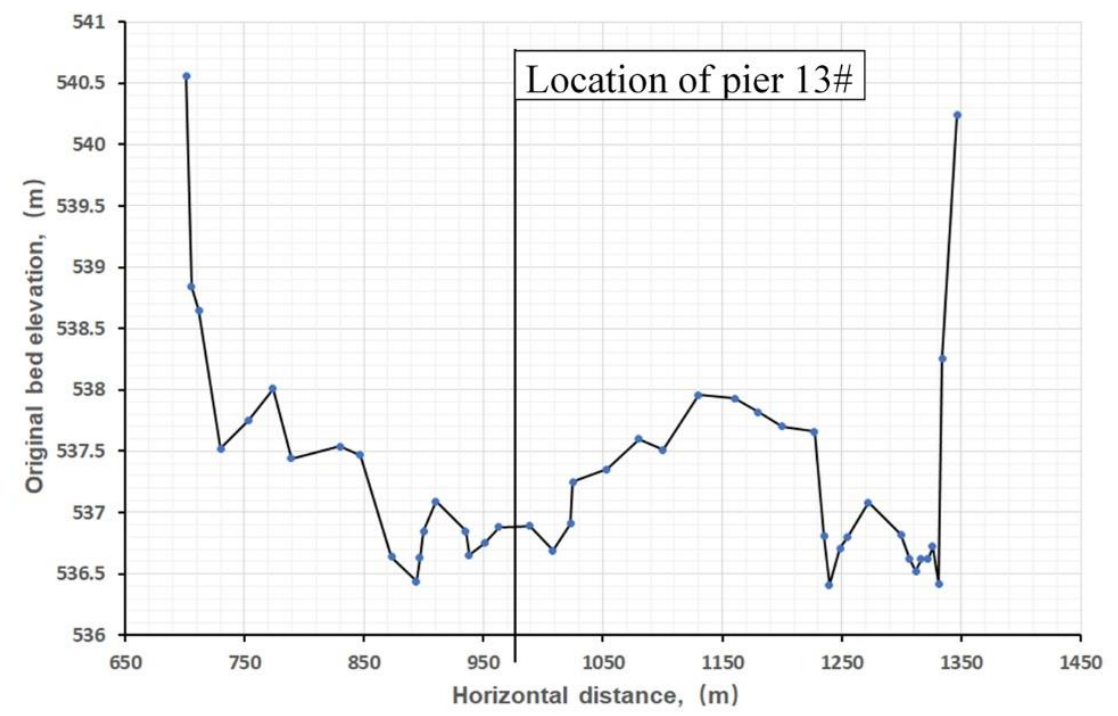

Fig. 4. B ed elevations at the bridge cross-section and location of pier 13\#

The channel bed elevations at the bridge site is shown in Fig. 4. The pier 13\# is located at the main channel, which is suffering most serious scour. Therefore, the pier $13 \#$ is taken to be analyzed herein. The water level at the bridge site is $540.95 \mathrm{~m}$ when the 100 -year return flow in the river channel is $7450 \mathrm{~m}^{3} / \mathrm{s}$.

The bed material was sampled using a geo-sampler near the pier 13\#. It was found that the sedimentary bed forms in more than five different layers with different sediments. The sediment size distributions for each layer was analysis and depictured in Fig. 5. The layer thickness of each layers was measured. The bed lays organize as: 1) Top layer: $d_{50}, d_{90}$ and $\eta\left(=d_{75} / d_{25}\right)$ is $0.15 \mathrm{~mm}, 1.0 \mathrm{~mm}$ and 1.9 , respectively. The thickness of this layer is about $7.0 \mathrm{~m}$, corresponding elevation of this layer ranges from 534.13 to $541.17 \mathrm{~m}$. 2) Second layer: $d_{50}, d_{90}$ and $\eta$ is $0.58 \mathrm{~mm}, 1.8 \mathrm{~mm}$ and 4.8 , respectively. The thickness of this layer is about $3.0 \mathrm{~m}$, corresponding elevation ranges from 530.98 to $534.13 \mathrm{~m}$. 3) Third layer: $d_{50}$, $d_{90}$ and $\eta$ is $0.87 \mathrm{~mm}, 5.8 \mathrm{~mm}$ and 24, respectively. The thickness of this layer is about 11.0 $\mathrm{m}$, corresponding elevation ranges from 519.92 to $530.98 \mathrm{~m}$. 4) Forth layer: $d_{50}, d_{90}$ and $\eta$ is $0.72 \mathrm{~mm}, 5.6 \mathrm{~mm}$ and 18 , respectively. The thickness of this layer is about $8.2 \mathrm{~m}$, corresponding elevation ranges from 519.92 to $511.77 \mathrm{~m}$. 5) Fifth layer: $d_{50}, d_{90}$ and $\eta$ is $0.041 \mathrm{~mm}, 0.40 \mathrm{~mm}$ and 7.4 , respectively. The thickness of this layer is about $17.30 \mathrm{~m}$, corresponding elevation ranges from 489.32 to $511.77 \mathrm{~m}$. 


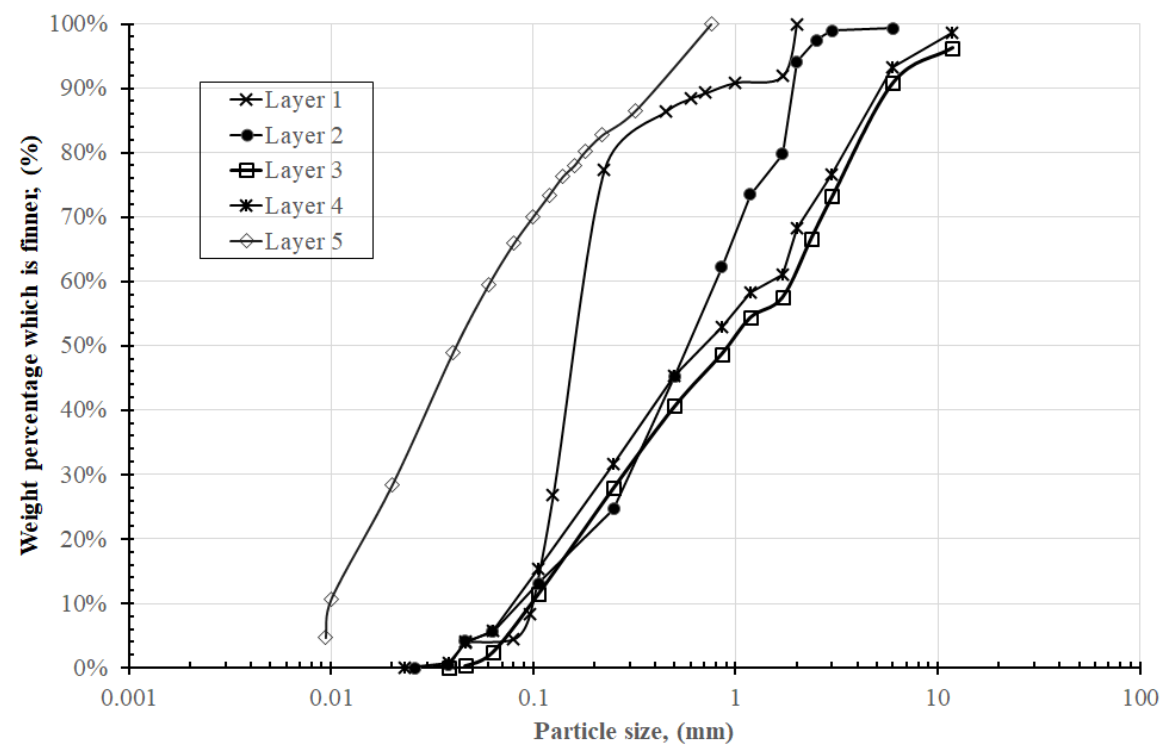

Fig. 5. Sediment size distributions of each layers

The approach velocity at piers is calculated using a two-dimensional depth averaged hydrodynamic model for the case of 100-year return flow at water discharge of $7450 \mathrm{~m}^{3} / \mathrm{s}$ and the water level $540.95 \mathrm{~m}$. It is obtained that the flow velocity at the pier $13 \#$ is $2.42 \mathrm{~m} / \mathrm{s}$ and the approach water depth is about $7.8 \mathrm{~m}$.

The above model is used to calculate the local scour depth of pier $13 \#$ at flow discharge of $7450 \mathrm{~m}^{3} / \mathrm{s}$. Herein, $K_{I}$ is taken to be 1.0 as the pier is consisted with two circular pile. $K_{2}$ is taken to be 1.1 as the pier is composed of two circular piles and the attack angle of flow is $15^{\circ} . K_{3}$ is taken to be 1.1 as bedform may occur at this high flow discharge. The calculated elevation of the local scour hole bottom is $528.28 \mathrm{~m}$. The contract scour depth due to the 32 piers is calculated to be $2.60 \mathrm{~m}$. Then, the bottom elevation of the scour hole around the pier $13 \#$ is $525.68 \mathrm{~m}$, which is lower than the measure level $529.59 \mathrm{~m}$. The result is reasonable as some refill in the scour hole would occur after high flow.

\section{Summary and Conclusions}

The simple model for calculation of local scour maximum depth around bridge piers sited on multi-layer of sedimentary bed is proposed based on HEC-18 revised by Richardson and Davis [4] and the formula of the repose angle of sediment particles proposed by Cheng [17]. This model considers the particle sorting when the scour proceeds. A survey is conducted to investigate the local scour depth around the pier of Guopan bridge which is sited on the Weihe River in Baoji City of China. The model prediction of scour depth is in line with the in-situ measured scour depth. This model may be reliable to calculate local scour maximum depth around bridge piers sited on multi-layer of sedimentary bed.

\section{Acknowledgements}

This work was supported by the CCCC Road \& Bridge Special Engineering Co., Ltd and the National Natural Science Foundation of China (No.51779137). 


\section{References}

[1] FHWA, Evaluating Scour at Bridges (Federal Highway Administration, Washington, DC, USA, $4^{\text {th }}$ edition, 1988).

[2] J. D. Schall, P. Davies, NCHRP Report 396 (Transportation Research Board, Washington, D.C., 1999).

[3] B. E. Hunt, NCHRP synthesis 396 (Transportation Research Board, Washington, D.C., 2009).

[4] E. V. Richardson, S. R. Davis, Hydraulic Engineering Circular N.18(HEC-18), Report FHWA NHI01-001 (US Department of Transportation, Federal Highway Administration, 2001).

[5] H. N. C. Breusers, G. Nicollet, H. W. Shen, J. Hydraul. Res., 15, 211-252 (1977).

[6] D. Gao, G. L. Posada, C. F. Nordin, Tech. Rep. FHWASA-93-076 (Federal Highway Administration, Washington, D.C., 1993).

[7] B. W. Melville, J. Hydraul. Eng. 123, 125-136 (1997).

[8] B. W. Melville, S. E. Coleman, Bridge Scour (Water Resource, LLC, 2000).

[9] D. M. Sheppard, B. Melville, H. Demir, J. Hydraul. Eng., 140, 14-23 (2014).

[10] A. O. Aksoy, G. Bombar, T. Arkis, M. S. Guney, Nephron Clin. Pract., 65, 26-34 (2017).

[11] N.S. Cheng, ISTHE, 4, 44-51 (1993) (in Chinese).

[12] Y. M. Chiew, B. W. Melville, Proceedings of the Institution of Civil Engineers-Water Management, 87, 215-224 (1989).

[13] A. J. Raudkivi, R. Ettema, J. Hydraul. Eng., 109, 338-350 (1983).

[14] G. Yu, S. K. Tan, S. Y. Lim, M. C. Ong, Proceedings of the XXX IAHR Congress: Processes and Integrated Management (International Association of Hydraulic Engineering and Research, Thessaloniki, 277-283, 2003)

[15] J. Hong, M. K. Goyal, Y. M. Chiew, L. Chua, J. Hydrol., 468-469, 241-248 (2012).

[16] K. Porter, R. Simons, J. Harris, Proceedings of Sixth International Conference on Scour and Erosion (Paris, 68-75 2012).

[17] K. Porter, R. Simons, J. Harris, T. F. Ferradosa, Proceedings of. $33^{\text {rd }}$ International Conference on Coastal Engineering (Santander, 2013). 